\title{
Beta-blocker therapy does not reduce ascending aorta wall shear stress in patients with bicuspid aortic valve
}

Bradley D Allen ${ }^{1 *}$, Michael Markl ${ }^{1,2}$, Alex J Barker ${ }^{1}$, Pim van Ooij ${ }^{1}$, James C Carr ${ }^{1}$, S C Malaisrie ${ }^{3}$, Robert O Bonow ${ }^{4}$, Preeti Kansal $\left.\right|^{4}$

From 18th Annual SCMR Scientific Sessions

Nice, France. 4-7 February 2015

\section{Background}

Ascending aorta (AAo) wall shear stress (WSS) may drive aorta dilatation in patients with bicuspid aortic valve (BAV) and $\beta$-blockers are first line medical therapy to slow this process. This study sought to determine if $\beta$-blocker therapy reduces AAo WSS in BAV patients.

\section{Methods}

Right-left coronary leaflet fusion BAV patients on $\beta$-blockers $(B B+)(n=30, M: F=23: 7$, age: $46 \pm 14$ years $)$ and not on $\beta$-blockers (BB-) ( $\mathrm{n}=30, \mathrm{M}: \mathrm{F}=23: 7$, age: $46 \pm 13$ years $)$ and healthy controls ( $\mathrm{n}=15$, age:43 \pm 11 years) underwent time-resolved, 3D phase contrast (4D flow) MRI. Patient groups were matched by systolic blood pressure (SBP), degree of aortic stenosis (AS), and AAo diameter (3.9 \pm 0.7 vs. $3.9 \pm 0.6 \mathrm{~cm}, \mathrm{p}=0.70)$. A $3 \mathrm{D}$ segmentation of the thoracic aorta was performed (MIMICS, Materlise, Belgium). Systolic 3D WSS was calculated in the thoracic aorta from 4D flow velocity acquisition and a sagittal maximum intensity projection (MIP) of WSS was generated.

\begin{tabular}{|c|c|c|c|c|c|c|}
\hline & \multicolumn{2}{|c|}{$\begin{array}{c}\text { Max WSS } \\
\left(R^{2}=0.42, p=0.02\right)\end{array}$} & \multicolumn{2}{|c|}{$\begin{array}{c}\text { Mean WSS } \\
\left(R^{2}=0.38, p=0.04\right)\end{array}$} & \multicolumn{2}{|c|}{$\begin{array}{c}\text { Peak Velocity } \\
\left(R^{2}=0.36, p=0.14\right)\end{array}$} \\
\hline & Beta & p-value & Beta & p-value & Beta & $\mathrm{p}$-value \\
\hline Beta-Blocker & -0.049 & 0.709 & -0.019 & 0.691 & -0.317 & 0.423 \\
\hline ACE-inhibitor or ARB & -0.044 & 0.802 & -0.002 & 0.978 & -0.734 & 0.143 \\
\hline Ejection Fraction & 0.013 & 0.310 & 0.004 & 0.382 & 0.027 & 0.416 \\
\hline Aortic Stenosis & 0.186 & 0.007 & 0.048 & 0.051 & 0.291 & 0.122 \\
\hline Aortic Insufficiency & -0.009 & 0.886 & 0.004 & 0.848 & -0.076 & 0.623 \\
\hline Sinus of Valsalva Diameter & -0.374 & 0.066 & -0.151 & 0.045 & -0.332 & 0.515 \\
\hline Mid-AAo Diameter & 0.016 & 0.908 & -0.014 & 0.774 & -0.142 & 0.729 \\
\hline Age & 0.002 & 0.783 & -0.003 & 0.147 & -0.015 & 0.396 \\
\hline Systolic blood pressure & -0.003 & 0.513 & 0.000 & 0.857 & -0.002 & 0.882 \\
\hline
\end{tabular}

Figure 1 Linear Modeling Findings. AAO = ascending aorta; $A C E=$ angiotensin converting enzyme; $A R B=$ angiotensin receptor blocker; WSS = wall shear stress.

${ }^{1}$ Radiology, Northwestern University, Chicago, IL, USA

Full list of author information is available at the end of the article

(c) 2015 Allen et al; licensee BioMed Central Ltd. This is an Open Access article distributed under the terms of the Creative Commons 


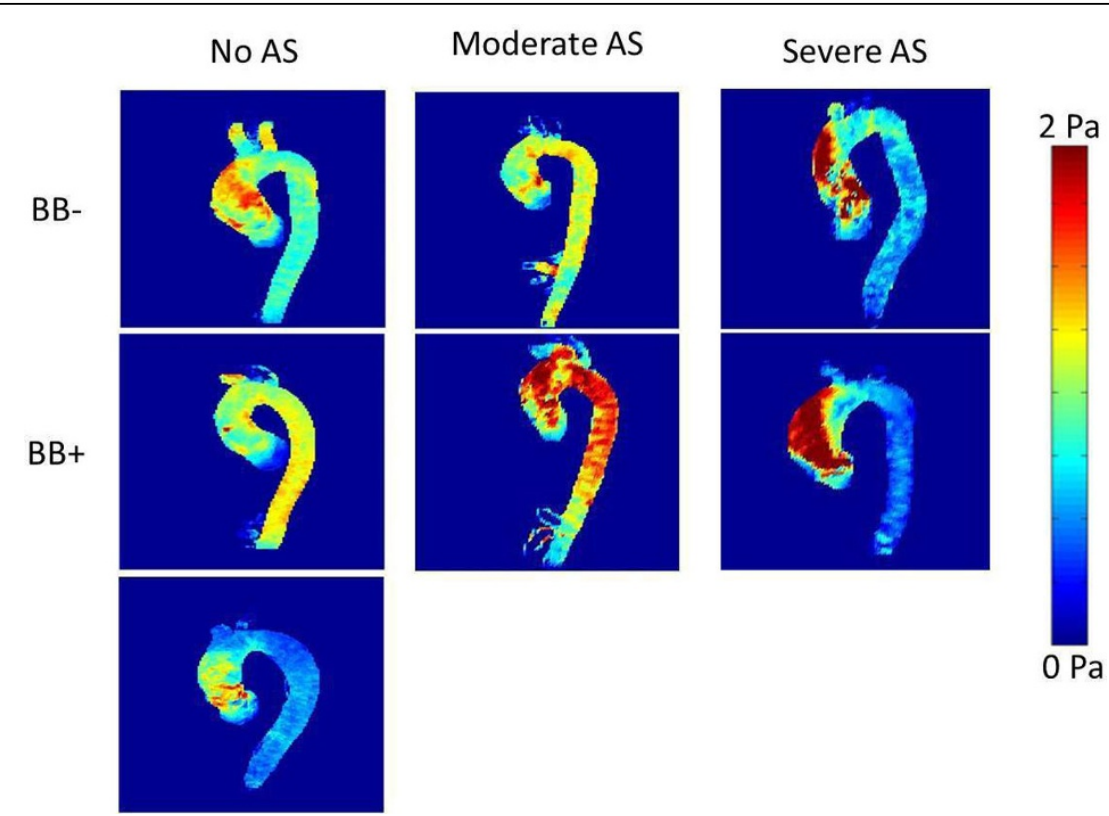

Figure 2 Systolic wall shear stress (WSS) maximum intensity projections (MIPs) in BAV patients with no aortic stenosis (AS), moderate AS, and severe AS from the BB+ and BB- group compared to a representative control subject.

Systole was defined as five cardiac time frames centered at the time frame with maximum average aorta velocity. A region of interest was drawn on the MIP from the sinus of Valsalva to the brachiocephalic artery to define the AAo, and this region was further subdivided into anterior and posterior segments. Max and mean systolic AAo WSS were extracted from each segment. Peak systolic AAo velocity was also measured. Quantitative results were compared with one-way analysis of variance and linear modeling was performed.

\section{Results}

Maximum and mean WSS were not reduced in the BB + group compared BB-patients in either the anterior AAo (maximum: $1.49 \pm 0.47 \mathrm{~N} / \mathrm{m}^{2}$ vs. $1.38 \pm 0.49 \mathrm{~N} / \mathrm{m}^{2}$, $\mathrm{p}=0.99$, mean: $0.76 \pm 0.2 \mathrm{~N} / \mathrm{m}^{2}$ vs. $\left.0.74 \pm 0.18 \mathrm{~N} / \mathrm{m}^{2}, \mathrm{p}=1.00\right)$ or posterior AAo (maximum: $1.45 \pm 0.42 \mathrm{~N} / \mathrm{m}^{2}$ vs. $1.39 \pm$ $0.58 \mathrm{~N} / \mathrm{m}^{2}, \mathrm{p}=1.00$; mean: $0.65 \pm 0.16 \mathrm{~N} / \mathrm{m}^{2}$ vs. $0.63 \pm$ $0.16 \mathrm{~N} / \mathrm{m}^{2}, \mathrm{p}=1.00$ ). Both patient groups had higher maximum and mean WSS relative to the control group $(\mathrm{p}=0.001$ to $\mathrm{p}=0.04)$. AAo peak velocity was elevated in patients compared to controls $(\mathrm{p}<0.01)$ but not significantly different for $\mathrm{BB}+$ vs. BB- groups $(\mathrm{p}=0.42)$. Linear models identified significant relationships between aortic stenosis severity and increased maximum WSS $(\beta=0.186, p=0.007)$ and between diameter at the sinus of Valsalva and reduced mean WSS $(\beta=-0.151, \mathrm{p}=0.045)$.

\section{Conclusions}

BB therapy does not reduce systolic WSS or peak velocity and does not impact WSS asymmetry in the AAo of rightleft fusion BAV patients. Further longitudinal studies are needed to clarify the impact of dose and duration of $\mathrm{BB}$ therapy on aortopathy.

\section{Funding}

NIH NCI 5R25CA132822-04, NIH NHLBI R01HL115828; AHA13SDG14360004, BAV Program at the Bluhm Cardiovascular Institute.

\section{Authors' details}

${ }^{1}$ Radiology, Northwestern University, Chicago, IL, USA. ${ }^{2}$ Biomedical Engineering, Northwestern University, Chicago, IL, USA. ${ }^{3}$ Cardiac Sugery, Northwestern University, Chicago, IL, USA. ${ }^{4}$ Medicine-Cardiology, Northwestern University, Chicago, IL, USA.

Published: 3 February 2015

doi:10.1186/1532-429X-17-S1-P399

Cite this article as: Allen et al: Beta-blocker therapy does not reduce ascending aorta wall shear stress in patients with bicuspid aortic valve. Journal of Cardiovascular Magnetic Resonance 2015 17(Suppl 1):P399. 